Military Technical College Kobry El-Kobbah, Cairo, Egypt

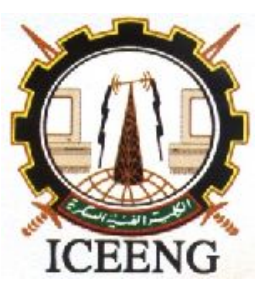

\author{
$10^{\text {th }}$ International Conference \\ on Electrical Engineering \\ ICEENG 2016
}

\title{
Design and Construction of Photovoltaic Biomass Hybrid Energy Power System to Supply A Residence in Egypt
}

\author{
By \\ Dr.Eng A. GADO*
}

\section{Abstract:}

Hybrid energy system has been seen as an excellent solution for electrification of rural place where the grid extension is difficult and economically not feasible.

The use of renewable energy sources is becoming very necessary due to the limited reserves of fossil fuels and global environmental concerns for the production of electrical power generation and utilization.

Solar energy is the most type of RESS pertaining the meteorological conditions of Egypt. This is due to the sunrise from 3000- 4000 hours/year with average insulations of $5-7 \mathrm{kwh} / \mathrm{m} 2 /$ day in all regions of Egypt. Also, photovoltaic (PV) power system is one of the most technologies used for conversion solar energy into electricity.

Also, Biomass resources in Egypt that can be used for energy production are classified into the following categories: non- Plantation biomass, fuel crops (energy plantations) and municipal waste. The estimated total amount of biomass is of the order of 60 million ton/y; their gross calorific value is about 855 million GJ, which is equivalent to about 20 million toe/y. On the other hand, the energy storage (ES) is also incorporated which could help cut electricity demand during peak periods and smoothing variations in power generation by variable solar power.

Solar PV and biomass with battery and converter are considered for the hybrid system. A case study was done in a rural village in Egypt. The main task is to find the suitable component size and operation strategy for system which results would lead to the design and planning a hybrid energy system.

The above concerns led to a desire to investigate the feasibility study of PV-biomassbattery storage based generator connected to grid, A study was conducted by collecting the solar radiation data, an average annual solar radiation was compared and a ranking system was performed. This system has a number of advantages over conventional power generation technologies. 
This paper depicts the different system components and their optimal combination for the efficient generation of electrical energy exploiting locally available resources. In this paper, a proposed approach has been introduced and applied for planning of PVbiomass systems on the electric utility of residential load in Egypt.

This approach includes a model for sizing of PV-biomass-battery storage systemsinteractive the electric utility grid and evaluating the generation of these systems. Also, a suggested model is presented and applied to assess the impact of this generation the capacity and energy displacement of conventional power supply (CPS), reduction in pollution and energy tariffs of the study electric utility. Learning mechanism utilizes a reference model that describes the desired performance. Finally, comparative analysis between the two developed controllers is conducted. It discusses the advantages and disadvantages of each controller algorithm.

\section{Keywords:}

PV , CPS, ES

* Higher Institute of Engineering and Technology -gharbia - tanta

\section{Introduction:}

Every year the demand of electrical energy is grow rapidly throughout the world. Also, 70\% of the population is live in rural areas. Generally the production of electrical energy generally depends on fossil fuels. As a result it increases $\mathrm{CO} 2$ emissions, which are not healthy for environment concern. So we should adopt the renewable energy by using hybrid systems.

Solar PV and biomass with battery and converter are considered for the hybrid system. Integrated biomass solar town concept is a concept which encourages local community to utilize biomass Waste. A geothermal-biomass hybrid renewable energy system is a proposed transformational energy plan to economically reduce its fossil fuel consumption and $\mathrm{CO} 2$ emissions [1]. 
On the other hand, the energy storage (ES) is also incorporated which could help cut electricity demand during peak periods and smoothing variations in power generation by variable solar power.

The main task is to find the suitable component size and operation strategy for system which results would lead to the design and planning of optimal hybrid energy system.

So, this paper discusses about an Integrated Biomass Solar Town for eco village in Egypt. Also, the paper attempts to develop the general model to find an optimal hybrid system combination of renewable energy resources for rural village ensuring the reliability of power supply. Different operation strategies can be implemented upon the various combinations. The energy stored in battery can be utilized during the time of night ensuring the optimal operation of system. The goal of optimal operation is to minimize cost and operating a system to yield best possible system performance where performance and cost are interlinked by each other. This is due to the fact that the sizing of components is related to the operation strategy adopted for the system.

\section{HYBRID ENERGY SYSTEM}

The design of optimal hybrid system is complex as the renewable energy supplies are not fixed it fluctuates depending upon the seasonal and geographical factor [2]. The fixed output from each scheme participating in system is not uniform. The call for optimized hybrid system while guaranteeing reliable operation is dependent upon component size and its characteristics with the optimal operation strategy. The parallel configuration of these individual schemes in hybrid system is used in this approach with the battery and converters for additional back-up especially for the output from solar panels. Flexibility, efficiency, reliability and economics are the factors held responsible for selecting the most optimum hybrid system combination of the proposed site. Solar PV and biomass with battery and converter for additional backup during the period of night.

\subsection{CASE STUDY}

The thesis work is based on a typical farming village situated in Egypt. Utility grid supply is already available at the site. This hybrid energy system is implemented to reduce the demand of the utility grid.

The hybrid system under consideration includes gasifier integrated 
network system, photovoltaic arrays and battery bank. The power output from the PV module is dependent on the available solar resource of the location. The system comprises of a gasifier-integrated network connected to the AC bus, the photovoltaic units are connected to the DC bus. The sizing of the hybrid system principally seeks to obtain the ratings of the generation units (photovoltaic arrays and the gasifier integrated network), and the capacity of the battery bank. The detailed system simulation is carried out using the software tool etap [3]. The annual average demand of the village is $4000 \mathrm{kWh}$ per day with a peak demand of $295 \mathrm{~kW}$.

\section{$\underline{2.2 \text { METHODOLOGY }}$}

- The grid connected electricity is imported in etap software tool, and the average electricity load per day and peak load is identified

- A PV sizing was modeled with solar radiation and by considering various de-rating factors.

- A suitable Biomass generator was opted and an assumption was made that 1 tons/day of biomass is available each day. A sizing of biomass generator was performed as per the target of power supply.

- Integration of HPS to grid system in order to supply electricity to the grid connected load

\section{SYSTEM DESIGN}

The site has an average solar irradiation of $6.7 \mathrm{kWh} / \mathrm{m} 2 /$ day . Biomass is available at the site. The biomass materials that have been used for power generation include rice husk, cotton stalk, mustard stalk, poultry litter and bagasse. The calorific value is $4000 \mathrm{~kJ} / \mathrm{kg}$. Biomass gasification converts solid biomass into more convenient gaseous form.

\subsection{Solar Panel}

The average daily solar energy input over the year can be found from the Solar Atlas that is about 5.4 to $7.1 \mathrm{kWh} / \mathrm{m} 2 /$ day depends on the area of operation. The rated capacity of PV is $200 \mathrm{~kW}$, It is operated for $4,385 \mathrm{hr} / \mathrm{yr}$ and generates an output of 358,686 $\mathrm{kWh} / \mathrm{yr}$. The demand is used for the calculation of the required number of solar 
panels [4].

$$
\mathrm{P}_{\mathrm{pv}}=\eta_{\mathrm{pv}} * \mathrm{~N}_{\mathrm{pvp}} * \mathrm{~N}_{\mathrm{pvs}} * \mathrm{~V}_{\mathrm{pv}} * \mathrm{I}_{\mathrm{pv}}
$$

Where $\eta p v$ represents conversion efficiency of PV module, Vpv the module operating voltage, Ipv the module operating current and Npvp, Npvs represents the number of parallel and series connected solar cells [5 ].

\section{$\underline{3.2 \text { Battery }}$}

PV power generation varies with the amount of sunlight shining on the panels at an instance, which results in lack of power generation during night time and cloudy weather. At such times, a battery bank is needed in order to provide smooth power to the load. Charges when excess electricity is produced from PV module and discharges when demand occurs. The maximum peak charge occurred between $12 \mathrm{pm}$ to $17 \mathrm{pm}$. A total energy of $133584 \mathrm{kWh} / \mathrm{yr}$ energy was introduced in the battery and $107,066 \mathrm{kWh} / \mathrm{yr}$ energy was consumed i.e. by discharging the battery.

\section{$\underline{3.3 \text { Converter }}$}

The converter output hooked to PV module converts direct current (DC) to alternate current (AC). A rated capacity $200 \mathrm{kw}$ converter was opted for $200 \mathrm{kw}$ of PV module [6]. The converter was operated for $6649 \mathrm{hy} / \mathrm{yr}$ with a total production of $401,530 \mathrm{kWh} / \mathrm{yr}$ energy and with an energy output of $361,378 \mathrm{kWh} / \mathrm{yr}$ from the system. Therefore $40,152 \mathrm{kWh} / \mathrm{yr}$ energy loss occurred due to system loss.

\section{$\underline{3.4 \text { Biomass generator }}$}

The fuels consumed by biomass generator are mainly agricultural waste, firewood, animal manure, cattle dung, human waste etc [7].

A rated capacity of $30 \mathrm{~kW}$ biomass based generator was used, the system was forced to use all the time. From the Fig. 2 it can be noticed that a maximum usage occurred at all the time from biomass generator. A total of $8,760 \mathrm{hrs} / \mathrm{yr}$ was used to generate a total production of $262,800 \mathrm{kWh} / \mathrm{yr}$, and with a bio-feed consumption of 124 tones/yr. the rate of fuel F, consumed by biomass generator producing power $\mathrm{P}$ is given by: 


$$
\mathrm{F}=\mathrm{aP}^{2}+\mathrm{bP}+\mathrm{c}
$$

Where $\mathrm{a}, \mathrm{b}$ and $\mathrm{c}$ are coefficients for generator

\section{APPLICATIONS}

The energy density of network is very much greater than that of solar PV and biomass thus the number of PV modules and biomass generator capacity are incremented step by step until the desired system is achieved. The system with higher reliability and lowest cost of energy per unit (KWh) is chosen as the optimal hybrid system. Figure 1 shows shows the hourly solar insolation and the power demand. Thus the total power generated from hybrid system at any time is:

$$
P(t)=\sum_{n=1}^{N_{n}} P_{n}+\sum_{s=1}^{N_{s}} P_{s}+\sum_{b=1}^{N_{b}} P_{b}
$$

Where $\mathrm{P}_{\mathrm{n}}$ is the network energy.

Figure 2 depicts the allocation of sources under different conditions. It shows that the power from solar photovoltaic is fully utilized to supply the load demand as well as charging the battery during day times, from this figure it is found also that the maximum demand of $221 \mathrm{~kW}$ occurs at 8:00 am is met by all energy sources. During that time, excess power available from the hybrid energy system is used for charging the battery bank. The monthly average electric production of each power system in a HPS is as shown in the Fig 3. The annual production by PV, generators is 318,831 $\mathrm{kWh} / \mathrm{yr}$, and 262,800 $\mathrm{kWh} / \mathrm{yr}$. annually, a total percentage contribution to electricity load by PV and generator are 40, and 33 percent. Also, battery storage shared by $6 \%$ however the remaining unmet electricity is purchased from grid i.e. a total of $170,099 \mathrm{kWh} / \mathrm{yr}$ of electricity i.e. 21percent. The remaining electricity is drawn from grid. Table 2 describe Block diagram of a proposed Solar PV/biomass hybrid energy system. Furthermore the biomass gasifier and SPV systems are operated during day times, from 6:00 AM to 9:00 PM (15hours per day). Utility grid supplies the power during night times. It is estimated that there is a considerable saving in the operating costs of the biomass gasifiers. The cash flow summary of each system is as shown in the Fig 5. 


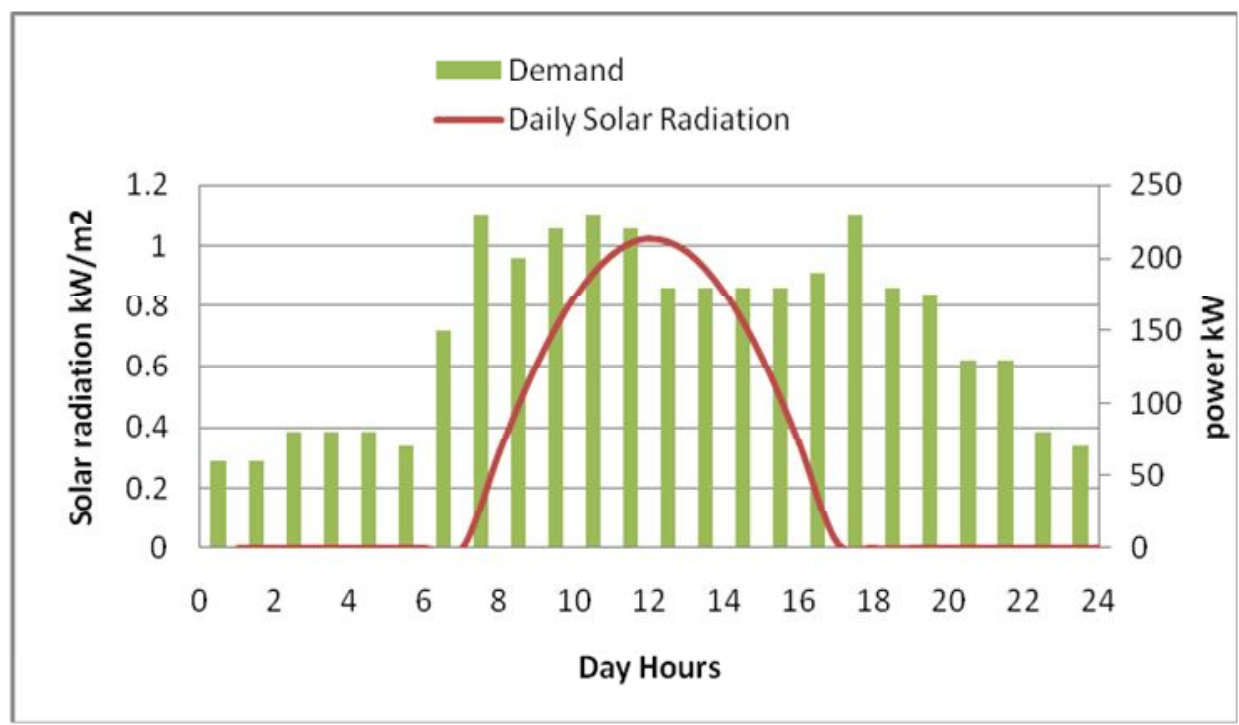

Figure 1. The hourly solar insolation and the power demand

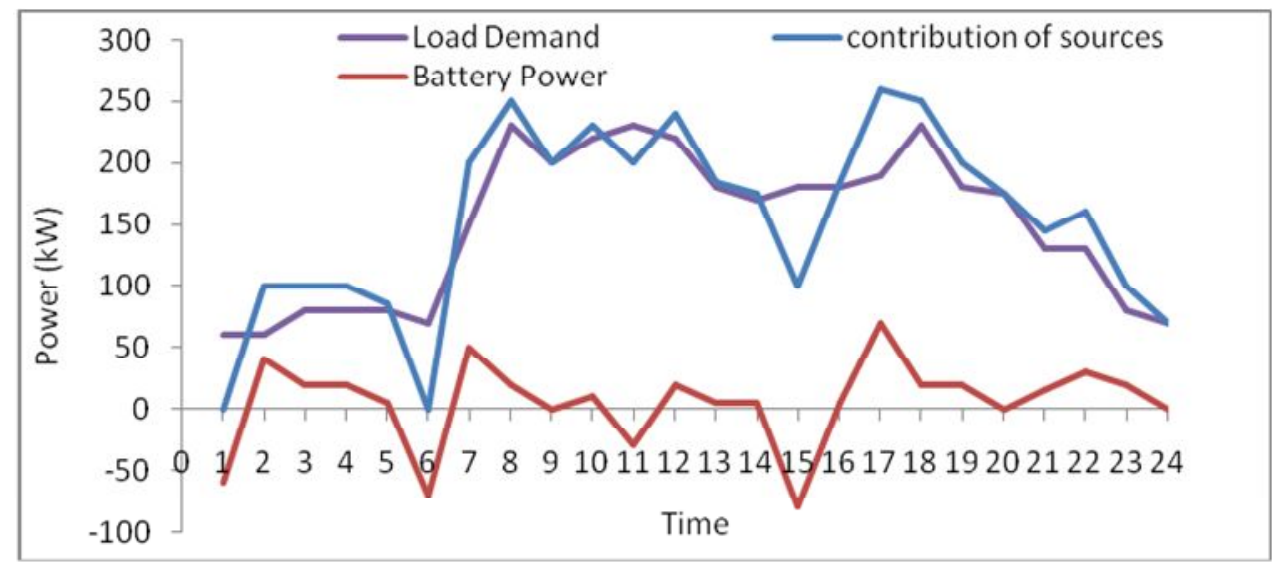

Figure 2. Optimal allocation sources 


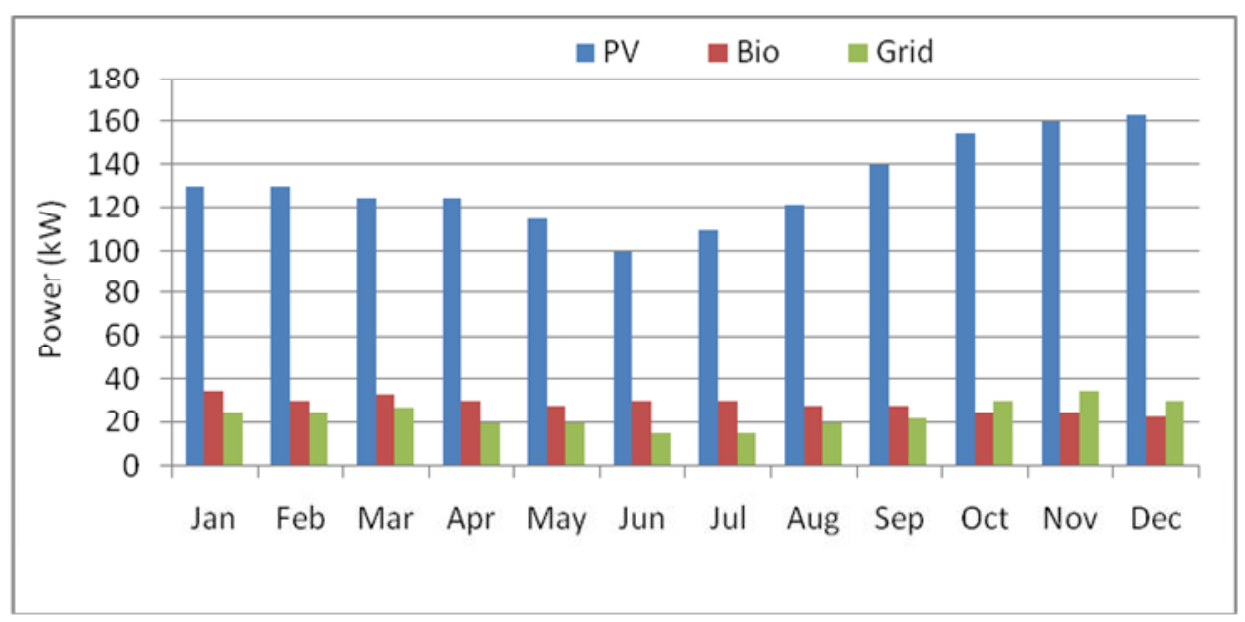

Figure 3. Average monthly electric production

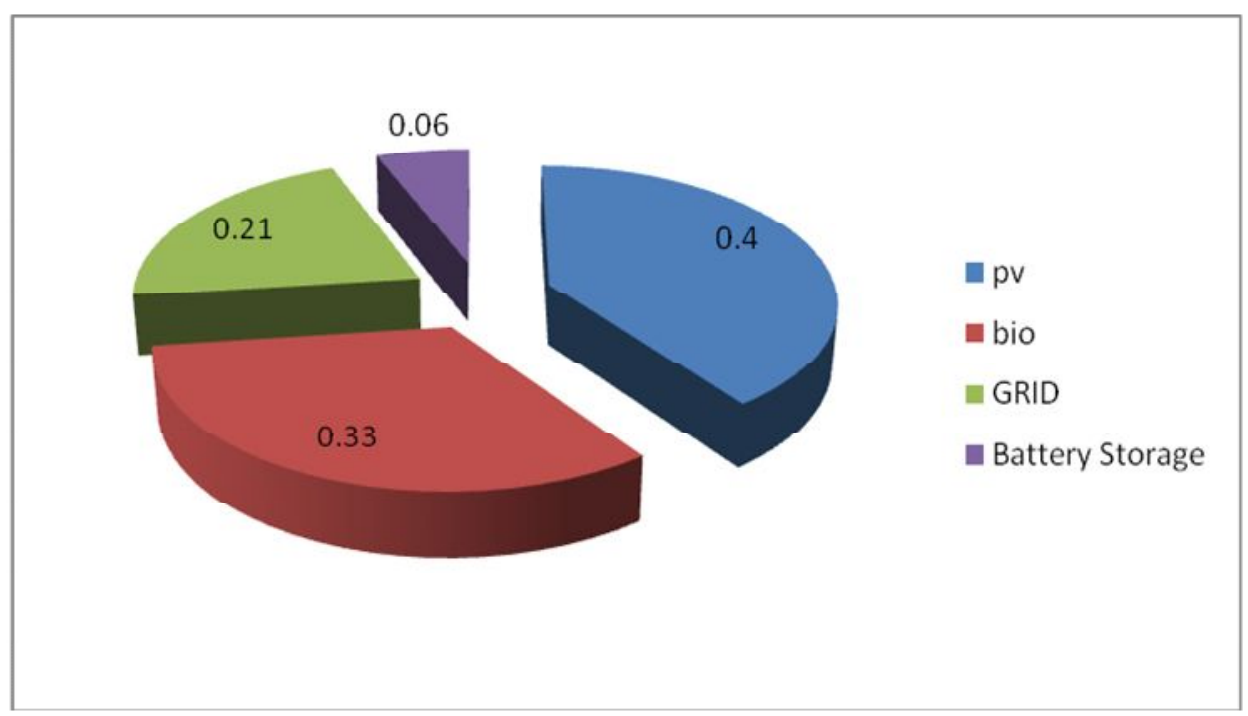

Figure 4. Annual contribution of different sources and storage

Figure 1 Block diagram of a proposed Solar PV/biomass hybrid energy system.

\begin{tabular}{|c|c|c|}
\hline Production & $\mathrm{KWh} / \mathrm{yr}$ & $\%$ \\
\hline PV array & 318831.1 & 0.4 \\
\hline Biomass Generator & 262800 & 0.33 \\
\hline Grid & 170099 & 0.21 \\
\hline Battery Storage & 55795.44 & 0.06 \\
\hline
\end{tabular}




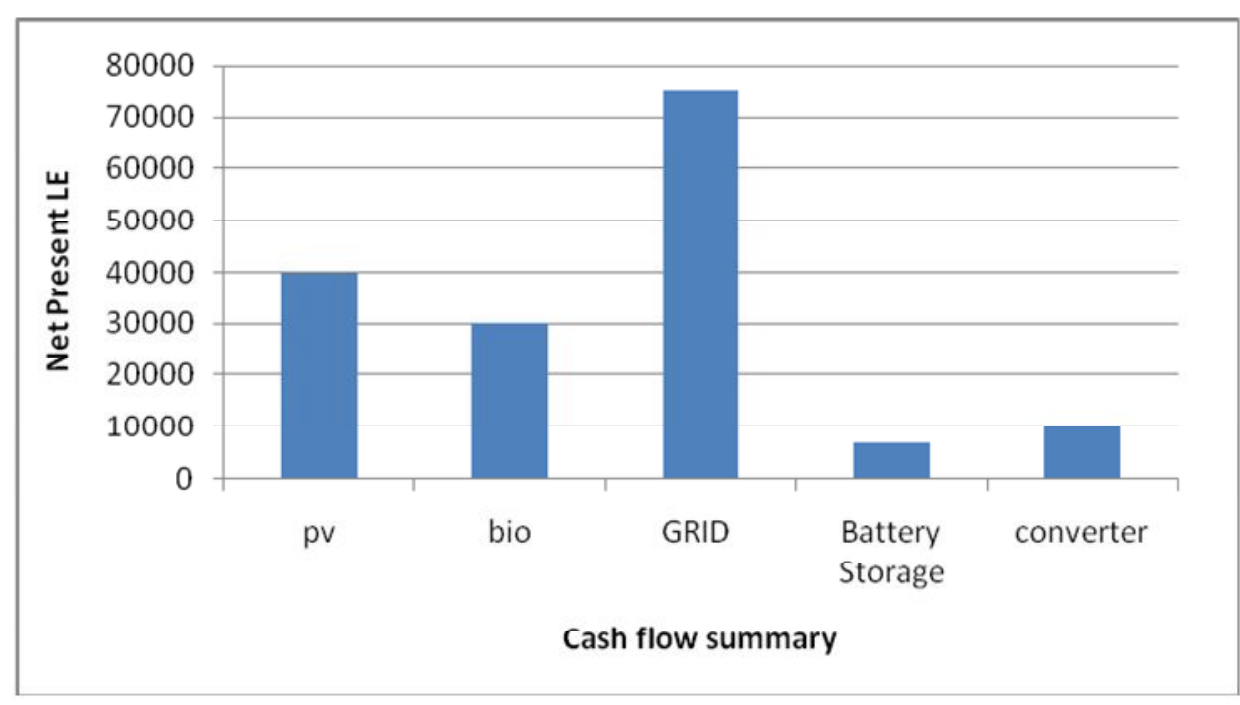

Figure 5. Cash flow summary of the system.

\section{Conclusions:}

Hybrid energy system is an excellent solution especially for electrification of remote rural areas. Where the grid extension is difficult and not economical. In this paper the analysis has been given for systematic procedure towards to plan a PV-Biomass based hybrid system and its Economic analysis including calculation of percentage savings, payback period analysis. An attempt to design HPS has made to explore the possibility of exploiting solar energy, and biomass to meet electricity load requirement for eco village in Egypt grid connected load. The performed feasibility study revealed that for annually varying electricity load a grid connected HPS system could be economical. Environmental friendly and viable solution. . The integration biomass gasifier in the system makes the system more sustainable as indicated and the usage of battery system for storage purpose has escalated the usage of renewable energy.

\section{References:}

1. M. A. Elhadidy and S. M. Shaahid, "Promoting applications of hybrid (wind+photovoltaic+diesel+battery) power systems in hot regions," Renewable Energy, vol. 29, no. 4, pp. 517-528, 2004.

2. Michael Boxwell, Solar Electricity Handbook, 6th ed. UK: Green stream Publishers, 2012. 
3. Mohan Kolhe Techno-Economic Optimum Sizing of a Stand-Alone Solar Photovoltaic System, , IEEE Transactions on Energy Conversion, VOL. 24, NO. 2, June 2009.

4. Optimal Sizing Method for Stand-alone Hybrid Solar-wind system with LPSP technology by using genetic algorithm; Hongxing Yang a, ${ }^{*}$, Wei Zhou a, Lin Lu a, Zhaohong Fang; Science Direct, Solar Energy 82 (2008) 354-367

5. Elhadidy MA, Shahid SM, "Optimum sizing of battery storage for hybrid (wind+diesel)", Renewable Energy; 18(1)( 1999)77.

6. A. A. Gado and A. EL- Zeftawy " Design and Economy of Renewable Energy Sources to supply Isolated Loads at Rural and Remote Areas of Egypt, $20^{\text {th }}$ International Conference on Electricity Distribution Prague, 8-11 June 2009.

7. A. EL-Zeftawy and A. A. Gado; "Design and Operating Photovoltaic Power System-Interactive the Electric Utility Supply Residential Loads in Egypt " $20^{\text {th }}$ International Conference on Electricity Distribution Prague, 8-11 June 2009 .

8. Building integrated photovoltaic (http://www.buildingsolar.com/technology.asp). 